ABDIMAS: Jurnal Pengabdian Masyarakat Universitas Merdeka Malang
Vol.6(2) May 2021, 166-175
L-ISSN: 2721-138X e-ISSN: 2548-7159
http://jurnal.unmer.ac.id/index.php/jpkm

\title{
Pendampingan dan Pengembangan Produk Udeng Sangga Braja dalam Rangka Melestarikan Ciri Khas Kota Batu
}

\author{
Shannaz Mutiara Deniar ${ }^{1}$, Yeyen Pratika², Tonny Dian Effendi ${ }^{1}$ \\ 'Departemen Hubungan Internasional, Fakultas Ilmu Sosial dan Ilmu Politik, ²Departemen Manajemen, Fakultas \\ Ekonomi dan Bisnis, Universitas Muhammadiyah Malang \\ Jl. Raya Tlogomas Malang, 65144, Indonesia
}

ARTICLE INFO
Received: 2020-12-16
Revised: 2021-02-09
Accepted: 2021-04-17
Keywords:
Public service Batu city,
Culture, Local wisdom,
Marketing, Udeng

\begin{abstract}
This community service program focuses on mentoring and developing small business based on culture. The partner of this activity is Paguyuban Sangga Braja which is located in Batu City. Paguyuban Sangga Braja has a cultural product called as udeng or the typical headband of Batu City. This udeng is designed with an emphasis on the history, philosophy and local wisdom of Batu City which also aims to become a traditional characteristic of Batu City. The problem faced by partner is that partner has an expectation that this cultural product will become a characteristic of Batu City, unfortunately people of Batu City are still not aware with the existence of this udeng. So, problem focus in this program is related to the marketing of this udeng in Batu City so that it is better known by public. To overcome this problem, the community service team helps partner in terms of assistance and improvement from the marketing aspect. Visual video and booklet used were chosen as the right alternative at that moment because it can be used to inform people about the existence of udeng and increase public awareness of this product in Batu City. In addition, the team also provided assistance to the IPR registration so that the copyright of Udeng could be more secure. The results of this community service show quite good results with video and booklet containing the philosophy and ways of using udeng as a marketing medium and an IPR certificate to protect the copyright of this udeng.
\end{abstract}

(C) 2021 Published by University of Merdeka Malang. This is an open access article distributed under the CC BY-SA 4.0 license

(https://creativecommons.org/licenses/by-sa/4.0/)

How to cite: Deniar, S. M., Pratika, Y., \& Effendi, T. D. (2021). Pendampingan dan Pengembangan Produk Udeng Sangga Braja dalam Rangka Melestarikan Ciri Khas Kota Batu. Abdimas: Jurnal Pengabdian Masyarakat Universitas Merdeka Malang, 6(2), 166-175. https://doi.org/10.26905/abdimas.v6i2.5171

\section{PENDAHULUAN}

Kota Batu adalah kota pariwisata berbasis pertanian di Provinsi Jawa Timur. Selain sebagai kota pariwisata, Kota Batu menyimpan sejarah dan budaya yang penting untuk dipelajari sekaligus dilestarikan. Situs Candi Songgoriti dan Gunung Panderman memuat sejarah panjang masyarakat di area Malang Raya mulai pada masa Kerajaan Kahuripan sampai kepada Singosari. Di sisi lain, masyarakat Kota Batu 
memiliki tradisi dan kebudayaan yang khas seperti kesenian Bantengan dan berbagai produk kerajinan alat tradisional.

Sebagian masyarakat Kota Batu yang peduli terhadap budaya lokal membentuk berbagai komunitas atau paguyuban yang sesuai dengan peminatannya masing-masing. Salah satu paguyuban budaya yang sangat aktif di Kota Batu saat ini adalah Paguyuban Sangga Braja. Paguyuban ini berdiri pada tahun 2017 dengan fokus perhatiannya mengarah pada produk budaya keris dan pusaka yang lain. Keris sendiri telah diakui sebagai warisan budaya khas Indonesia oleh UNESCO (Pitakasari, 2011). Oleh karena itu, paguyuban ini tidak hanya sebagai sarana berkumpul bagi para pecinta keris dan pusaka yang lain, melainkan juga penting dalam konteks pelestarian budaya.

\section{LOKASI MITRA}

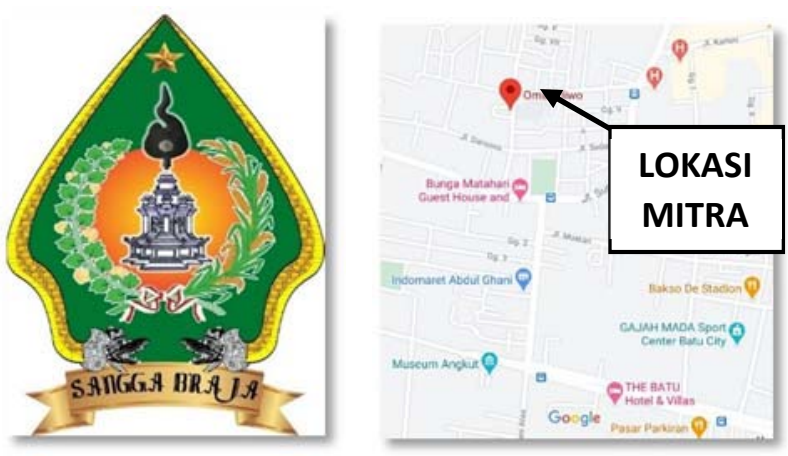

Gambar 1. Logo Paguyuban Sangga Braja Kota Batu Gambar 2. Lokasi Paguyuban Sangga Braja

Di Kota Batu sendiri terdapat cukup banyak paguyuban yang memiliki perhatian khusus pada seni dan budaya. Namun, Paguyuban Sangga Braja dipilih karena paguyuban ini memiliki keunikan sendiri dibandingkan paguyuban lain, khususnya terkait pengembangan kreasi budaya. Paguyuban Sangga Braja sangat berperan aktif dalam melakukan kegiatan-kegiatan masyarakat yang berbasis pada promosi nilai-nilai asli leluhur budaya Jawa, seperti berpartisipasi dalam festival budaya Kota Batu, pameran kebudayaan, gelaran budaya, hingga forum diskusi pertukaran antar budaya. Paguyuban ini juga kerap aktif dalam kegiatan Gerakan Masyarakat Sapu Bersih Pungut Sampah di Kali (Saber Pungli) di Kota Batu. Namun, kegiatan-kegiatan paguyuban ini biasanya juga diadakan di Omah Jiwo yang terletak di pusat kota. Omah Jiwo digunakan sebagai ruang diskusi berkumpulnya pemerhati budaya Kota Batu atau sebagai tempat mini pameran yang pernah dilakukan paguyuban ini. Sehingga, lokasi paguyuban ini pun bertempat yang sama dengan Omah Jiwo yang ditunjukkan pada Gambar 2.

Selain fokus kepada keris dan pusaka lainnya, pada perkembangannya Paguyuban Sangga Braja juga mulai mengembangkan satu produk budaya yaitu berupa udeng atau ikat kepala khas Kota Batu. Di Indonesia sendiri, udeng khas daerah telah banyak diperkenalkan untuk menjadi identitas daerah suatu daerah. Seperti halnya udeng lain yang memiliki ciri khas tersendiri, udeng khas Kota Batu juga 
ABDIMAS: Jurnal Pengabdian Masyarakat Universitas Merdeka Malang

Volume 6, No. 2, May 2021: 166-175

memiliki perbedaan dan keunikan dibandingkan udeng lain yang ada di Indonesia. Konsep dan bentuk dari udeng khas Kota Batu ini digali dari sejarah dan filosofi kearifan lokal Kota Batu. Hal yang paling menonjol adalah bentuknya yang mewakili atau menggambarkan topografi Kota Batu yaitu diapit dua gunung, Gunung Arjuno dan Gunung Panderman.

Model udeng khas Kota Batu ini oleh Paguyuban Sangga Braja diberi nama Sima Bhawana. Dalam Bahasa Sansekerta, Sima berarti macam, sedangkan Bhawana berarti daerah atau tempat; dalam hal ini yang dimaksudkan adalah daerah Kota Batu. Model ini juga disebut sebagai udeng model Arjuna karena menyerupai bentuk Gunung Arjuna di bagian belakang udeng tersebut. Kontribusi Paguyuban Sangga Braja dalam upayanya melestarikan budaya daerah adalah dengan membuat udeng yang mencirikan identitas, makna dan filosofisnya sebagai kekhasan Kota Batu.

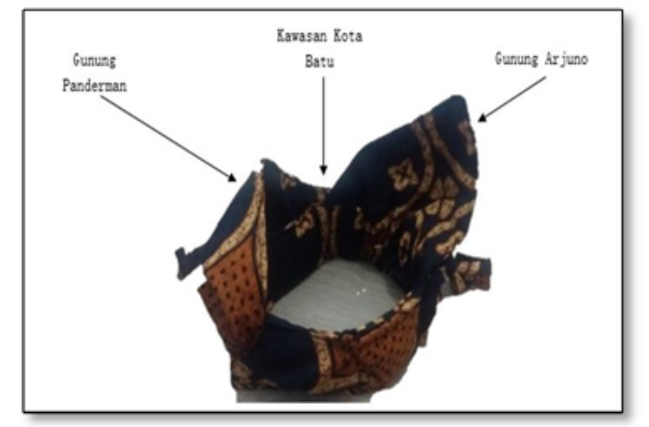

Gambar 3. Bentuk udeng khas Kota Batu marketing berdasarkan topografi Kota Batu

Udeng Sima Bhawana sudah diperkenalkan dan diakui oleh Pemerintah Kota Batu dan menjadi salah satu ikon dari kota wisata ini (Rahman, 2019). Paguyuban Sangga Braja bahkan aktif melakukan pameran tingkat lokal dan nasional untuk mempromosikan produk budaya ini. Kreativitas dalam menciptakan udeng ini sendiri termotivasi agar Kota Batu memiliki ciri khas budaya yang memang selama ini belum cukup tergali. Pada awalnya, paguyuban ini tidak memiliki tujuan untuk mengkomersialisasikan udeng tersebut. Namun, permintaan untuk memproduksi udeng yang semakin meningkat mendorong paguyuban memanfaatkan anggota yang memiliki kemampuan menjahit agar dapat memproduksi produk budaya ini. Dari hasil penjualan udeng tersebut, sebagian disisihkan untuk dana paguyuban dan sisanya diserahkan kepada pengrajin. Dengan sistem produksi seperti ini, hasil yang didapat masih belum signifikan karena selama ini pembeli udeng ini hanya sebatas pemerintah daerah dan komunitaskomunitas yang menggelar acara di Kota Batu saja. Strategi pemasaran yang dilakukan udeng tersebut juga hanya dilakukan secara tradisional saja, yakni melalui pameran budaya yang diikuti dan sistem konsinyasi ke toko oleh-oleh yang masih sangat terbatas. Hal ini dikarenakan keterbatasan Sangga Braja untuk merepresentasikan dan mensosialisasikan produknya dengan memanfaatkan media elektronik audio visual. Padahal, produk budaya udeng khas Kota Batu ini memiliki potensi yang sangat tinggi ke depannya sehingga paguyuban ini perlu dibantu dalam hal mengatasi masalah pemasarannya.

Pemasaran adalah proses di mana perusahaan memiliki keterikatan dengan pelanggan, membangun hubungan yang kuat dengan pelanggan, dan menciptakan nilai pelanggan agar mendapatkan nilai dari pelanggan itu sendiri sebagai gantinya (Kotler \& Armstrong, 2018). Untuk itu, pemanfaatan media 
elektronik berupa pembuatan video profil udeng khas Kota Batu ini diperlukan sebagai alternatif promosi. Video promosi dimaksudkan di sini adalah video yang digunakan untuk mempromosikan produk dengan lebih detail dalam durasi yang lebih panjang daripada video iklan (Artanto et al., 2018). Video ini sendiri digunakan sebagai alat promosi mitra pada saat mengikuti pameran kebudayaan dan juga pada tahap selanjutnya dapat ditayangkan melalui media sosial agar menjangkau masyarakat lebih luas. YouTube berbasis video dinilai sebagai salah satu media sosial yang paling efektif untuk meningkatkan brand awareness pada produk budaya (Imam et al., 2017).

Selain itu, mengingat produk budaya udeng khas Kota Batu ini diciptakan dengan filosofi yang cukup mendalam, maka perlu dilakukan upaya untuk menjaga hak cipta atas udeng tersebut yang mengarah pada aspek intelektual. Upaya ini juga dilakukan agar tidak ada pihak lain yang mengklaim bahwa produk budaya ini sebagai hasil pemikirannya, apalagi mengakuinya sebagai ciri khas kota lain. Atas dasar permasalahan tersebut, paguyuban merasa perlu dilakukan suatu cara agar hal ini tidak terjadi melalui pendaftaran hak cipta di Kementerian Hukum dan Hak Asasi Manusia. Namun, paguyuban tidak memiliki akses informasi yang cukup mengenai hal ini.

\section{METODE}

Kegiatan pengabdian masyarakat ini berfokus pada aspek pemasaran dan intelektual, maka metode pelaksanaannya disesuaikan dengan kedua aspek tersebut. Pada pelaksanaan kegiatan pengabdian ini terdapat 3 orang yang terlibat aktif dalam keseluruhan kegiatan, yakni ketua dan dua anggota paguyuban yang sekaligus tim pencipta udeng khas Kota Batu ini. Adapun kegiatan yang dilakukan dalam pengabdian ini sebagai berikut: (1) Pelatihan manajemen pemasaran yang digunakan untuk meningkatkan pemahaman dan kesadaran mitra tentang pentingnya pemasaran untuk mengenalkan produk budaya ini; (2) Perbaikan alat promosi dimana mitra dikenalkan untuk memanfaatkan penggunaan media elektronik audio visual sebagai media promosi agar pada saat mempromosikan dengan lebih informatif dan menarik; (3) Difusi dan penerapan iptek dimana mitra diajak aktif untuk membuat video dan booklet sebagai media promosi produk budaya udeng ini; (4) Pendampingan yang dilakukan untuk memberikan pengarahan kepada mitra terkait tujuan dan proses pendaftaran HKI (Hak Kekayaan Intelektual).

\section{Metode kegiatan}

Adapun rincian dari kegiatan-kegiatan tersebut dituangkan dalam beberapa metode seperti yang akan dijelaskan berikut.

\section{Metode diskusi dan penyuluhan}

Metode ini bertujuan untuk mengarahkan mitra agar memiliki pemahaman mengenai manajemen produksi yang baik sehingga proses produksi dapat lebih efektif dan efisien. Selain itu, metode ini juga bertujuan agar mitra memperoleh pemahaman mengenai hak cipta dan bagaimana proses pendaftaran HAKI terkait produknya. Selain itu, tim juga melakukan penyuluhan untuk memberikan pemahaman 
ABDIMAS: Jurnal Pengabdian Masyarakat Universitas Merdeka Malang

Volume 6, No. 2, May 2021: 166-175

kepada mitra mengenai pentingnya pengemasan (packaging) yang menarik sehingga produk memiliki nilai jual yang lebih tinggi. Hal ini dikarenakan selama ini mitra hanya menggunakan plastik kresek sebagai kemasannya.

\section{Metode pelatihan}

Metode ini bertujuan untuk mengaplikasikan solusi-solusi yang ditawarkan sehingga mitra dapat mempraktikkan secara langsung. Terkait pelatihan yang dimaksudkan di sini adalah mitra diajak untuk membuat video mengenai udeng tersebut di mana mitra sekaligus dijadikan talent actor dalam video tersebut. Dalam hal ini, video tersebut digunakan sebagai media promosi sekaligus edukasi kepada masyarakat mengenai produk budaya udeng Kota Batu ini. Namun, perlu diketahui bahwa pada pengabdian saat ini pelatihan yang dilakukan masih sebatas dalam hal pembuatan video promosi sebagai media elektronik saja sehingga belum mengarah pada pemanfaatan media sosial sebagai alternatif promosi.

\section{Metode pendampingan}

Metode pendampingan yang dilakukan dalam kegiatan ini adalah dengan memberikan pengarahan kepada mitra terkait fungsi, tujuan dan proses pendaftaran Hak Kekayaan Intelektual (HKI) terkait produk budaya udeng tersebut.

\section{HASIL DAN PEMBAHASAN}

Pelaksanaan pengabdian yang bekerja sama dengan mitra Paguyuban Sangga Braja Kota Batu ini menghasilkan beberapa hal sesuai dengan aspek yang ingin dikembangkan dan ditingkatkan. Adapun hasil tersebut terbagi dalam dua sub judul sebagai berikut.

\section{Aspek pemasaran}

Pada pelaksanaan perbaikan aspek pemasaran ini dilakukan dengan memberikan pelatihan kepada mitra mengenai 4P (Product, Place, Price, and Promotion) yang merupakan dasar dalam ilmu pemasaran. Penerapan konsep 4P pada produk budaya telah dilakukan pada penelitian ilmiah sebelumnya dan menunjukkan adanya perbaikan pada usaha kain tradisional (Vitasari \& Setiawan, 2019). Untuk itu, pemahaman mengenai konsep 4P ini juga diterapkan dalam produk budaya udeng khas Kota Batu dengan menekankan pada atribut produknya, yaitu perbaikan pengemasan (packaging) agar udeng tersebut lebih memiliki nilai jual. Daya tarik dalam kemasan sebuah produk harus memiliki daya tarik secara estetika maupun fungsinya (Cenadi, 2000). Dalam hal ini, mitra diberi alternatif-alternatif bentuk kemasan yang bisa digunakan untuk menarik nilai jual dari Udeng.

Berkenaan dengan aspek produk, packaging juga menjadi bagian yang tidak terpisahkan dalam produk budaya udeng ini. Selama ini, harga yang ditawarkan untuk satu buah udeng adalah Rp80.000,00 sementara biaya produksi untuk satu udeng adalah Rp70.000,00. Mitra hanya mengambil keuntungan sebesar Rp10.000,00 saja untuk kas paguyuban. Dalam aspek harga, tim pengabdian memberi solusi dengan menambah alternatif produk yang lebih eksklusif dengan dilengkapi kemasan yang lebih memiliki 
nilai jual. Produk yang lebih eksklusif adalah udeng dengan bahan kain batik yang lebih berkualitas seperti batik tulis, batik cap, maupun batik print. Harga yang ditetapkan pun bisa berbeda tergantung dengan kualitas kain batik yang digunakan sendiri. Paguyuban Sangga Braja juga memiliki motif kain batik segi empat yang menjadi ciri khas pada udeng tersebut. Corak atau motif yang ekslusif ini juga bisa menjadi alternatif produk yang bisa ditawarkan kepada konsumen. Dengan memiliki banyak alternatif produk, maka produk udeng ini dapat memiliki kekhususan yang bisa disesuaikan dengan keinginan konsumen.
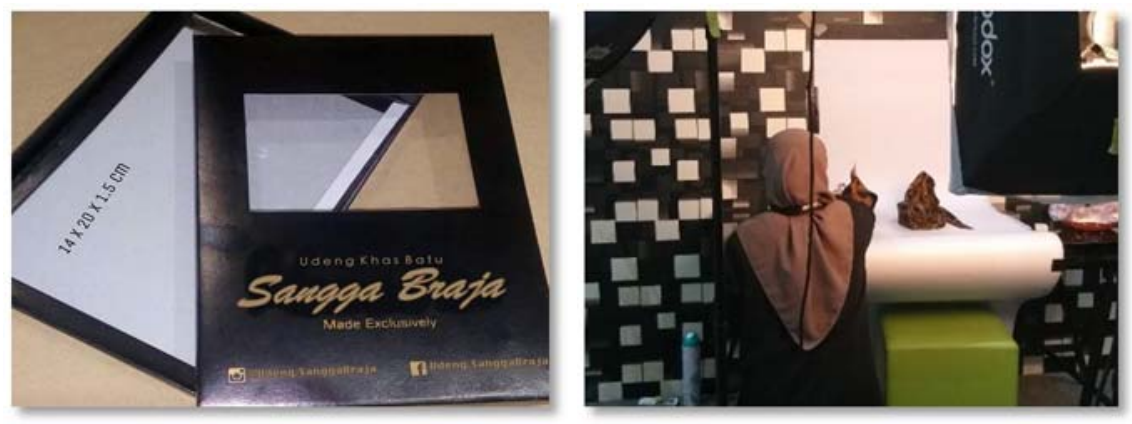

Gambar 4. Contoh kemasan dan proses pembuatan booklet

Produk udeng khas Kota Batu merupakan produk baru yang masih dalam tahap pengenalan sehingga membutuhkan strategi untuk menyadarkan (aware) masyarakat mengenai produk ini terlebih dahulu. Kesadaran merek dinilai dapat mempengaruhi keputusan seseorang dalam membeli sebuah produk karena konsumen memiliki kemampuan untuk mengenali produk tersebut (Ramadayanti, 2019). Selain itu, dalam hal place dan promotion, paguyuban juga diajak terlibat aktif dalam melakukan pembuatan video dan booklet yang digunakan sebagai media promosi secara online. Mitra yang cukup rajin mengikuti pameran yang diselenggarakan oleh pemerintah setempat juga perlu didukung dengan media promosi yang baik. Promosi yang dilakukan secara intens dapat menunjang dalam proses peningkatan kesadaran merek (Schivinski \& Dabrowski, 2015). Keterlibatan mitra dalam menunjang proses e-marketing ini dapat dilihat dengan personel mitra yang menjadi talent dalam video pengenalan dan cara penggunaan udeng khas Kota Batu. Video dan booklet ini digunakan untuk dapat meningkatkan aspek pemasaran produk budaya udeng, khususnya pada kesadaran masyarakat mengenai produk budaya udeng khas Kota Batu ini.
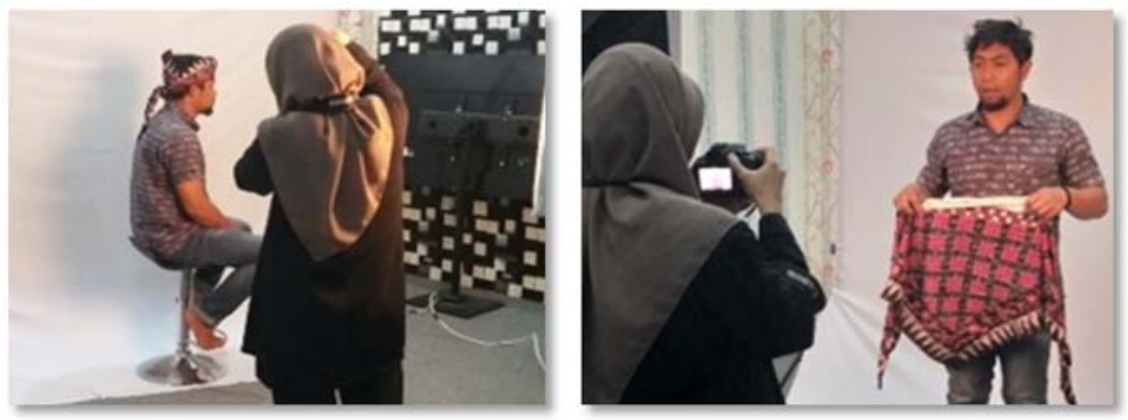

Gambar 5. Proses pembuatan video udeng khas Kota Batu 
ABDIMAS: Jurnal Pengabdian Masyarakat Universitas Merdeka Malang Volume 6, No. 2, May 2021: 166-175

Video promosi tersebut menjelaskan secara singkat profil paguyuban yang telah menghasilkan produk budaya udeng khas Kota Batu. Selanjutnya, video diteruskan dengan penjelasan tata cara penggunaan udeng mulai dari teknik melipat kain batik hingga memasangkannya di kepala. Talent juga menjelaskan setiap angkah-langkah dalam melipat kain udeng tersebut disertai dengan penjelasan makna filosofis dari teknik melipat tersebut. Di akhir video, talent juga menjelaskan mengenai makna filosofis yang menyeluruh dari bentuk udeng khas Kota Batu. Video ini bertujuan agar masyarakat paham mengenai teknik membuat dan juga memahami apa makna yang tersimpan di balik udeng tersebut. Dalam hal promosi, video digunakan untuk display saat paguyuban mengikuti pameran atau festival kebudayaan.

Meskipun pembuatan video berjalan baik, namun pada saat pelaksanaan terdapat kendala dalam pengambilan video dan gambar. Hal ini dikarenakan talent pada video tersebut memang tidak terbiasa di depan kamera sehingga perlu dilakukan pengambilan gambar beberapa kali untuk mendapatkan hasil yang lebih baik. Namun demikian, mitra sangat kooperatif dan aktif dalam proses pembuatan video tersebut sehingga kendala yang ada dapat teratasi dengan baik.
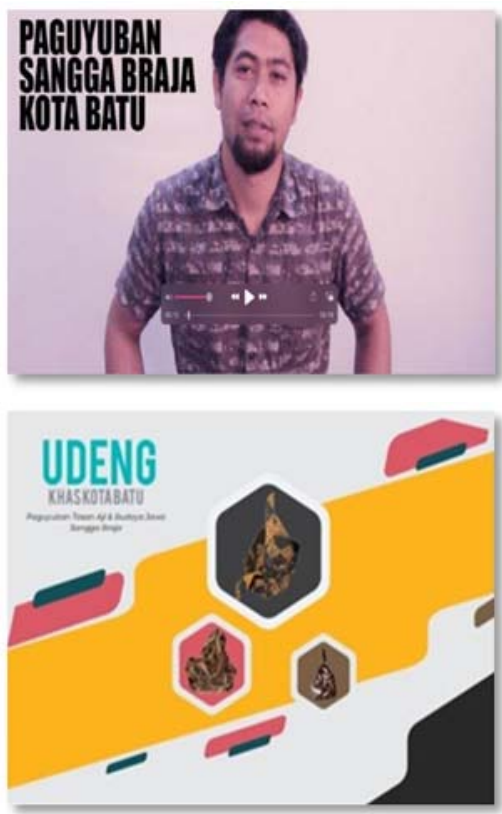

Gambar 6. Tangkapan layar video untuk media promosi

Gambar 7. Bentuk booklet udeng khas Kota Batu
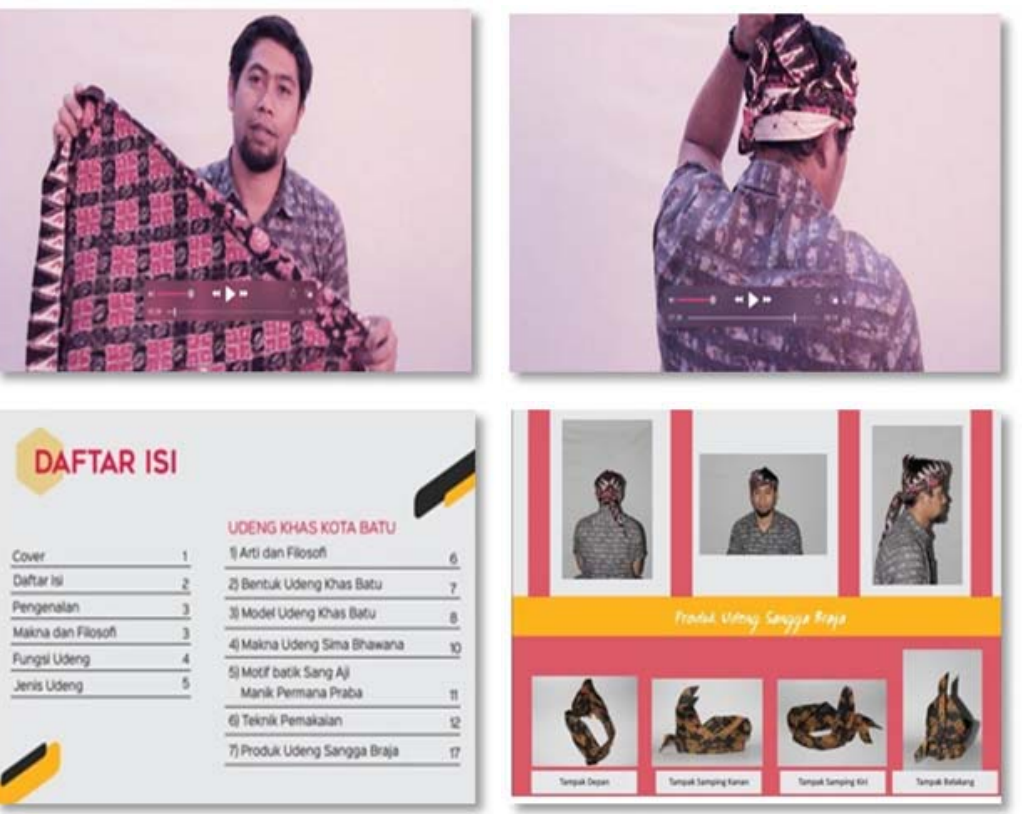

Selain itu, pembuatan booklet mengenai udeng khas Kota Batu juga dilakukan sebagai media informasi bagi pelanggan dan calon pelanggan Paguyuban Sangga Braja. Booklet ini sendiri berisi informasi terkait sejarah dan filosofi singkat dari udeng khas Kota Batu ini yang juga bertujuan sebagai media edukasi bagi masyarakat. Di dalam booklet ini terdapat informasi mengenai kegunaan udeng dan sejarah, serta makna filosofis dari udeng dan juga motif batik karya Paguyuban Sangga Braja. Model udeng Kota Batu didasari dari logo Kota Batu yang bertuliskan candrasengkala yang berarti berkarya 
untuk memperbaiki dunia. Simbol Gunung Arjuna yang terlihat dari bentuk model udeng juga bertujuan agar si pengguna tampak gagah seperti gunung serta berilmu dan berbudi luhur. Di dalam booklet juga diberikan informasi mengenai teknik pemakaian udeng.

Mitra sangat terlibat aktif dalam pembuatan booklet ini, terutama dalam menjelaskan makna dan filosofi udeng tersebut yang bersumber dari sejarah dan budaya Kota Batu. Peningkatan penjualan pada produk ini sendiri mulai terlihat dengan semakin meningkatnya jumlah permintaan atas produk budaya ini setelah dilakukan strategi pemasaran tersebut.

\section{Aspek intelektual}

Pendampingan dalam pendaftaran Hak Kekayaan Intelektual (HKI) untuk produk udeng Sima Bhawana dimaksudkan untuk memberi perlindungan dari hasil kreativitas dan karya intelektual dari Paguyuban Sangga Braja sebagai kreatornya. Di samping itu, dalam hal produksi, Paguyuban Sangga Braja mendapat keuntungan ekonomi dari kepemilikan hak. Sebagai produk budaya yang memiliki identitas khas dan nilai-nilai filosofis, udeng Sima Bhawana merupakan salah satu invesi yang harus dilindungi. Selama ini, praktik paten atau pendaftaran HKI belum dinilai mampu melindungi pengetahuan tradisional yang merupakan bentuk ciptaan pengetahuan dan teknologi masyarakat (Tuuk, 2017). Kepentingan komunitas pemilik ciptaan terkadang diabaikan, padahal komersialisasi pengetahuan dan teknologi masyarakat juga terus meningkat. Walaupun pemerintah Kota Batu telah mengakui udeng ini sebagai ciri khas dari Kota Batu dan telah disosialisasikan kepada masyarakat, namun sebagai bentuk perlindungan ekspresi budaya, promosi kreativitas, dan pelestarian warisan budaya, pendaftaran model udeng khas Kota Batu ini juga menjadi penting.

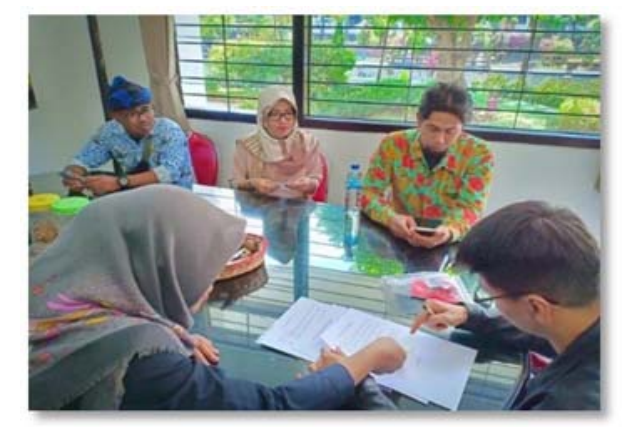

Gambar 8. Proses pendampingan pendaftaran HKI

Pendampingan pendaftaran HKI untuk model udeng Kota Batu Sima Bhawana difasilitasi oleh Sentra HKI Universitas Muhammadiyah Malang. Tim pengabdian bersama mitra menyusun syarat-syarat pendaftaran HKI seperti video tutorial pemakaian udeng dan booklet yang menjelaskan mengenai kekhasan Udeng Sima Bhawana. Model udeng Sima Bhawana disesuaikan dengan kondisi riil topografi Kota Batu. Di bagian belakang terdapat bentuk gunungan yang menggambarkan deretan Gunung Arjuna kemudian berjejer ke bagian sisi kanan adalah Gunung Welirang, Gunung Biru, dan Panderman. Sedangkan di sisi sebelah kiri menggambarkan hamparan tanah yang subur sebagai ciri Kota Batu 
ABDIMAS: Jurnal Pengabdian Masyarakat Universitas Merdeka Malang

Volume 6, No. 2, May 2021: 166-175

sebagai kota pertanian, kemudian pemukiman masyarakat dan pintu masuk utama ke Kota Batu. Di dalam video tutorial dijelaskan bagaimana praktik menggunakan udeng Sima Bhawana. Paguyuban Sangga Braja memang telah memproduksi udeng yang siap pakai agar konsumen tidak perlu bingung, namun sebenarnya secara riil udeng Kota Batu menggunakan sebuah kain batik berbentuk segi empat yang memiliki corak khusus. Dalam proses pemakaiannya pun memiliki nilai filosofis. Dengan nomor pencatatan 000157138, udeng khas Kota Batu tercatat dalam Surat Pencatatan Ciptaan yang dikeluarkan oleh Direktorat Jenderal Kekayaan Intelektual, Kementerian Hukum dan HAM.

Udeng khas Kota Batu merupakan ekspresi seni budaya dari masyarakat Kota Batu yang dipahami menjadi bagian yang integral dalam kehidupan sosial masyarakat Kota Batu. Hasil kreativitas adalah wujud dari dharma bakti individu/kelompok tersebut kepada masyarakat (Margono, 2015). Paguyuban Sangga Braja tidak memandang bahwa udeng ini adalah produk budaya yang hanya boleh dimiliki oleh paguyuban saja, namun bersifat terbuka. Identitas dan nilai filosofis dalam udeng ini harus dipahami oleh seluruh masyarakat Kota Batu dan boleh digunakan secara luas. Bahkan, ketua paguyuban sempat menyatakan bahwa jika ada masyarakat Kota Batu yang ingin memproduksi udeng sangat dipersilahkan karena sebenarnya udeng Sima Bhawana adalah milik masyarakat Kota Batu.

\section{SIMPULAN DAN SARAN}

Program pengabdian masyarakat ini berfokus pada pendampingan dan pengembangan usaha kecil berbasis budaya. Udeng Sima Bhawana diperkenalkan oleh Paguyuban Sangga Braja yang didasarkan pada sejarah, filosofi, dan kearifan lokal Kota Batu. Dalam aspek pemasaran, kurangnya pengetahuan mengenai 4P (product, place, price, dan promotion) dapat diatasi dengan pendampingan dan pelatihan. Pada aspek intelektual pelestarian kebudayaan lokal diatasi dengan pembuatan video promosi dan pendaftaran HKI. Kolaborasi dan partisipasi aktif dari mitra ditunjukkan dengan sangat antusias dalam setiap proses pelaksanaan pengabdian masyarakat ini.

Pengabdian selanjutnya dengan mitra ini dapat dilakukan dengan memberikan mitra pendampingan secara langsung tentang teknik e-marketing dengan memanfaatkan media sosial ataupun platform terkait yang dapat mendorong peningkatan penjualan produk budaya udeng ini. Selain itu, kain udeng bermotif batik yang dimiliki mitra sebagai udeng dapat pula didaftarkan untuk mendapatkan hak ciptanya karena motif batik tersebut juga merupakan karya seni yang memiliki nilai filosofinya.

\section{UCAPAN TERIMA KASIH}

Ucapan terima kasih kepada Direktorat Penelitian dan Pengabdian Kepada Masyarakat (DPPM) Universitas Muhammadiyah Malang sebagai sponsor utama dalam kegiatan pengabdian ini dan semua pihak yang membantu penyelesaian program pengabdian ini. 


\section{DAFTAR PUSTAKA}

Artanto, A. T., Zuhroh, F., \& Wibisono, A. B. (2018). Karakter visual pada video promosi sebagai upaya memperkenalkan UKM Sidoarjo. Jurnal Ilmu Komputer dan Desain Komunikasi Visual, 3(2), 46-57.

Cenadi, C. S. (2000). Peranan desain kemasan dalam dunia pemasaran. Nirmana, 2(2), 92-103. https://doi.org/10.9744/nirmana.2.2.

Imam, C., Budiarjo, H., \& Hidayat, W. (2017). Perancangan Media promosi video YouTube koleksi Sanggar Gubug Wayang Mojokerto berbasis budaya sebagai upaya meningkatkan brand awareness. Journal Art Nouveau, 6(1).

Kotler, P. T., \& Armstrong, G. (2018). Principles of Marketing (17th ed.). United Kingdom: Pearson Education Limited.

Margono, S. (2015). Hukum Hak Kekayaan Intelektual. Edisi Kesatu. Bandung: Pustaka Reka Cipta.

Pitakasari, A. R. (2011, Agustus 25). Setelah Pengakuan UNESCO, Indonesia Semestinya Bentuk Lembaga Keris. Republika. Retrieved from: https://republika.co.id/berita/nasional/umum/11/08/25/ lqh5nx-setelah-pengakuan-unesco-indonesia-semestinya-bentuk-lembaga-keris.

Rahman, M. D. (2019). Dinas Pariwisata Kota Batu Kenalkan Udeng Sima Bhawana Arjuna. Times Indonesia. Diakses dari: https://www.timesindonesia.co.id/read/news/214166/dinaspariwisata-kota-batu-kenalkan-udeng-sima-bhawana-arjuna

Ramadayanti, F. (2019). Peran brand awereness terhadap keputusan pembelian produk. Jurnal Studi Manajemen dan Bisnis, 6(2), 111-116. https://doi.org/10.21107/jsmb.v6i2.6690

Schivinski, B., \& Dabrowski, D. (2015). The impact of brand communication on brand equity through Facebook. Journal of Research in Interactive Marketing, 9(1), 31-53.

https://doi.org/10.1108/JRIM-02-2014-0007

Tuuk, W. P. (2017). Perlindungan Hak Kekayaan Intelektual (HKI) terhadap pengetahuan dan teknologi tradisional menurut Undang-Undang Nomor 13 Tahun 2016 tentang Paten. Lex Privatum, 5(4).

Vitasari, P., \& Setiawan, G. (2019). Metode 4P sebagai salah satu cara dalam meningkatkan strategi penjualan pada industri kain tradisional. Prosiding Seminar Nasional Teknik Industri, Lhokseumawe. 